\title{
SWARA ve COPELAND Yöntemleri ile Global Tedarik Zinciri Yönetimini Etkileyen Faktörlerin Önem Düzeylerinin Değerlendirilmesi ${ }^{1}$
}

\author{
Assessment of the Importance Level of the Factors Affecting Global Supply Chain \\ Management Through SWARA and COPELAND Methods
}

\section{Dr. Öğr. Üyesi Serdar Yarlıkaş² - Cafiye Arslaner ${ }^{3}$}

Başvuru Tarihi: 20.09.2018

Kabul Tarihi: 23.12.2019

Öz

Global tedarik zinciri yönetiminde hedefe ve başarıya ulaşmak için doğru işletilmesi gereken bir takım faktörler vardır. Bunlar kritik başarı faktörüdür ki bir firmanın başarısı için çok önemli ve gerekli olan faktörleri ve işlemleri ifade etmektedir. Global tedarik zincirini en etkin şekilde yönetmek için yapılan detaylı literatür taraması sonucu ortaya çıkan kritik başarı faktörleri şu şekilde sıralanmıştır; Benzersiz ürün ve hizmet, Çalışanların iş yapma arzusu, Düşük maliyetler, üstün kalite, uygulama hızı, Yerel gereklilikleri ve talepleri yerine getirme ihtiyacı, Kapasitenin Artırılması, Mevcut pazar taahhütlerini yerine getirme gerekliliği, rekabet edebilen bir insan kaynă̆l, Etkin ve rekabetçi küresel tedarik zinciri stratejisi, Yönetmelikler, Etkin bir risk yönetimi ve bilgi yönetim sistemi, Etkin bir talep planlama sistemidir. Bu çalışmada, öncelikle, global tedarik zinciri yönetimini etkileyen başarı faktörleri incelenmiş, daha sonra, takip eden aşamada, bu başarı faktörlerinin önem sıralamaları ve önem düzeyleri SWARA yöntemi uygulanarak belirlenmeye çalışılmıştır. Ayrıca, SWARA yöntemi ile elde edilen sonuçların sağlamasının yapılabilmesi için COPELAND yöntemi kullanılmıştır. SWARA yöntemi uygulaması için kullanilan karar verme anketi Kocaelinde bulunan bir küresel tedarik zinciri şirketindeki uzmanlara uygulanmıştır. Bu anket ile elde edilen verilerin analizi sonucunda en önemli kriterin 0,108 değeri ile 'uygulama hız', en düşük öneme sahip kriterin ise 0,050 değeri ile 'yönetmelikler' olduğu görülmüş̧ür. Bu sonuç ise küresel tedarik zinciri ile ilgili literatürdeki çalışmaların sonuçları ile benzerlik göstermektedir. Bu çalışma ile elde edilen kriter ă̆ırlıkları firmalar tarafindan global tedarik zinciri yönetim sistemlerinin seçiminde kullanılabilir.

Anahtar Kelimeler: Küreselleşme, Global Tedarik Zinciri, SWARA, COPELAND, Başarı Faktörleri

\footnotetext{
${ }^{1}$ Bu çalışma, 'International Conference on Empirical Economics and Social Sciences (ICEESS'18), June 27-28, 2018 /Bandırma - Turkey' adlı konferansta sözlü olarak sunulan 'Küresel Tedarik Zinciri Yönetimini Etkileyen Kritik Başarı Faktörlerinin Belirlenmesi' isimli özet bildiriden yararlanarak, ilgili çalışmanın anket ve karar verme uygulaması yapılarak SWARA ve COPELAND yöntemleri ile analiz yapılıp genişletilerek oluşturulmuş halini içeren özgün ve yeni nitelikte bir çalışmadır.

2 Kocaeli Üniversitesi, İktisadi ve İdari Bilimler Fakültesi, serdar.yarlikas@kocaeli.edu.tr, ORCID ID: 0000-0001-5087-955X

3 Kocaeli Üniversitesi, Sosyal Bilimler Enstitüsü, Üretim Yönetimi ve Pazarlama Anabilim Dalı Yüksek Lisans Öğrencisi, cafiye.arslaner@gmail.com, ORCID: 0000-0002-3804-1284
} 


\section{Abstract}

There are a number of factors that need to be applied to reach the goal and achieve the success in the management of global supply chain. These are the critical success factors that state the significant and required ones for the success of a company. Critical success factors obtained through a detailed literature review in order to manage the global supply chain in the most efficient manner are listed as follows; Unique product and service, Employee desire to do business, Low costs, superior quality, speed of implementation, Need to fulfill local requirements and demands, Increasing Capacity, Need to fulfill current market commitments, Competitive human resources, Efficient and competitive global supply chain strategy, Regulations, Effective risk management and information management system, An effective demand planning system. In this study, first of all, the success factors affecting global supply chain management were investigated, after that, in the following step, the importance level and order of importance of these success factors were tried to be determined by applying the SWARA method. Besides, COPELAND method was used so as to prove the results obtained through the SWARA method. The decision-making survey required for the implementation of SWARA method was applied to the experts in a global supply chain company in Kocaeli. As a result of the analysis of the data obtained thanks to this survey, it was observed that the most important criterion was the implementation rate with 0.108 and, on the other hand, the lowest criterion was the regulations with the value of 0.050. This result resembles the results of the studies associated with global supply chain. The criteria weights obtained through this study can be used by firms in the selection of global supply chain management systems.

Keywords: Globalization, Global supply chain, SWARA, COPELAND, Success Factors

\section{Giriş}

Tedarik zinciri teknik olarak, malzeme tedariki işlemlerini yerine getiren daha sonra üretim işlemleri sonucunda malzemelere ve mamullere dönüştürüp daha sonra oluşan üretim sistemlerinde katma değer yaratan zincirdir. Bu zincir, malzemelerin sağlanması, bu malzemelerin ara ve tamamlanmış ürünlere dönüşümü ve tamamlanmış ürünlerin müşterilere dağıtımı fonksiyonlarını yerine getirir. Tedarik zincirinin yönetimi ise, hammaddenin sisteme girip son kullanıcıya teslim edilmesine kadar gerçekleşen zincirdeki hem yukarı (upstream, girdi sağlayanlar), hem de aşağı (downstream, dağıtım ve pazarlama sonrası hizmetler) tüm malzeme ve bilgi akışlarının kontrol ve koordinasyonunu kapsayan bir faaliyettir (Eymen, 2007, s.7; Ganeshan ve Harrinson, 1995; Min ve Zhou, 2002, s.231-249; Teigen, 1997).

Tedarik zincirleri artık sadece yurt içindeki tedarikçilerle ve işletmelerle sınırlı kalmamaktadır. Dolayısıyla artan bir hızla ulusal sınırları geçen ve küreselleşen tedarik zincirleri ağları da oluşturulmaktadır. Tedarik zincirlerinin küreselleşmesine yönelik mevcut eğilim, küreselleşmenin gerçekten ne anlama geldiği ile ilgilidir. Açıkça, küreselleşme, malların sınır ötesi hareketine ve bir sektör içindeki rekabetçi tedarik zincirlerine karşı küresel rakiplerin ve fırsatların ortaya çıkmasına neden olmaktadır. Bununla birlikte, yöneticiler genellikle, küresel 
pazar ile tek bir pazar arasındaki farklılıkları sorgulamaktadır. Çünkü aynı koşulların çoğu her ikisinde de mevcuttur. Bu doğru olsa da, küreselleşmenin gerektirdiği ithalat ve ihracat benzeri küresel piyasalardaki karmaşıklığı, tek bir ülkedeki üretim işlemleri karmaşıklığından daha fazladır ve küresel ortamda rekabet etme yeteneği, genellikle sınır ötesi ticaretle ilgili yani "Global Tedarik Zinciri Yönetiminde (GTZY) ortaya çıkan teknik ve ekonomik detayları ve şartları” anlamaya dayanmaktadır (Mentzer vd., 2006).

Günümüz pazarlarındaki şiddetli rekabet; endüstriyel teknolojideki ilerlemeler, talebin ve tedarik kaynaklarının artan küreselleşmesi, bilgi bulunabilirliğindeki muazzam gelişmeler, bol miktarda risk sermayesi ve yaratıcı iş tasarımları tarafından yönlendirilmektedir (Bovet ve Sheffi 1998, s. 14-22). Yoğun rekabet içeren pazarlarda, pazar payının basit analizlerle değerlendirilmesi ve incelenmesi, karlılığı sağlamak için artık yeterli değildir ve bu nedenle şirketler, rekabetçi alanlarını ya da kâr alanlarını yeniden tanımlamaya odaklanırlar (Bovet ve Sheffi 1998, s. 14-22; Tekin, vd. 2005, s.115-129).

Önceden işletme yönetiminde daha kritik olduğu düşünülen pazarlama, satış ve finans gibi temel işletme fonksiyonları ile karşılaştırdığımızda bilginin üretilmesi ve işletme birimleri arasında paylaşılması ikinci dereceden önemli sayılmaktaydı (Ross, 1998, s. 2-3; Croxton vd., 2001, s.13-32). Günümüzde ise bilgi üretimi ve paylaşılması, bilişim teknolojilerinin kullanımı ile, artık işletme yönetiminde ve dolayısıyla tedarik zinciri yönteminde daha önemli ve daha etkin bir hale gelmektedir.

Genel olarak tüm dünyada etkisini gösteren küreselleşme tedarik zincirlerini de etkilemektedir. Bilişim teknolojilerinin yaygınlaşması bilgi akışını hızlandırmış, zaman, mekân ve mesafe algılarını değiştirmiştir. Dolayısıyla bu durum kültürleşme sürecine ivme kazandırarak küresel ortak değerlerin oluşmasını sağlamıştır. Ve bu da tedarik zincirlerinin yönetimine yansımıştır. $\mathrm{Bu}$ sebeple tedarik zincirleri daha kapsamlı ve karmaşı bir yapıya bürünmektedir. Bilginin, hammaddenin, mal ve hizmetlerin artan bir şekilde uluslararası dağıtım ve paylaşıma girmesiyle dünya tek bir pazar haline gelmiştir. Tedarik zinciri unsurlarının da değişimini ve güncel değişimlere uyum sağlamasını kaçınılmaz kılmıştır (Ateş, 2007, s.110).

Global tedarik zincirindeki her bir çalışanın amacı, en yeni bilgiyi zincirdeki diğer çalışanlara iletmektir. Dolayısıyla bu şekilde daha mükemmel arz ve talep dengesi sağlanmaktadır. Global tedarik zincirinin karmaşıklığı, bir uçtan bir uca bir bütün olarak gözlemlenmesini zorlaştırabilir. Ancak başarılı tedarik zinciri yöneticileri, bu bakış açısını geliştirmek için firmalar arasındaki iletişim ve işbirliğini iyi tasarlanmış bir plan ile gerçekleştirmeyi amaçlamaktadırlar. Dolayısıyla global tedarik zinciri yönetimini etkileyen faktörlerin ve bu faktörlerin önem düzeylerinin belirlenmesi gerekmektedir.

Bu belirlenen faktörler doğrultusunda iyi tasarlanmış ve iyi yapılandırılmış bir küresel tedarik zinciri yönetimi oluşturulabilir, yani global tedarik zincirlerinde bir takım stratejik problemlerle karşı karşıya kalınması durumunda bu faktörlerin önem düzeyleri dikkate alınarak global 
tedarik zinciri yönetiminde karşılaşılacak sorun ya da problemlere çözüm üretmede daha etkin bir karar verme mekanizması oluşturulabilir.

\section{Literatür Taraması}

Küreselleşme kelimesi; genişleyen uluslararası ticaret, sınırları aşan finansal kaynak aktarımı, artan diş yatırımlar, büyüyen çok uluslu işletmeler ve ortak girişimler anlamına gelmektedir. İktisatçı Richard Lipsey'e göre "bir ekonominin küreselleşmesi birçok bireysel ülke ekonomisindeki finansman ve üretim sektörlerinin artan ölçülerde bütünleşmesi” olarak tanımlanmaktadır. Dünyanın değişik ülkelerindeki fabrikalardan temin edilen parçaların nihai montaj için bir başka ülkede toplanması ve üretim sürecinin değişik aşamalarında finansmanının çeşitli ülkelerin sermaye piyasalarında sağlanması bu tanıma uygun bir örnek teşkil etmektedir (Akın, 1998, s.7).

Küresel tedarik zinciri yönetimi, ülke sınırları dışına çıkarak tüm ulusları ve kıtaları içermektedir. Diğer bir ifade ile çok uluslu bir yapıyı sergiler. Günümüzde bu durumun en iyi örneklerinden biri olan büyük bir küresel ekonomik güce sahip ve tüm kıtalara ihracat ve ithalat faaliyetlerinde bulunan Çin ve ilişkisel partnerlerini sayabiliriz. Dolayısıyla küresel tedarik zinciri yönetimi; kıtalararası satıcılardan (tedarikçiden) malzemeleri (ham madde, yarı mamul, mamul ve alt montaj malzemelerini vb.) üretim sürecine taşıyan sonrasında ise, son ürüne dönüşmüş ürünleri nihai kıtalararası müşterilere ulaştıran büyük ve karmaşık yapının tüm yönlerini içermektedir (Onat, 2002, s.38).

Küresel alanda rekabetçi kalabilmek için, işletmeler bölgesel olarak dağılmış tedarik zincirini bir bütün olarak anlamak zorundadırlar. Sistem, parçaların etkileşimi üzerine düşünülmüş olup, parçaların içindeki dinamizmin ve etkileşimin sistemin sonuçlarına etkisi beklenenden daha fazladır. Müşteri problemlerinin çözümü için hizmet eden, özellikle dağıtım ve online sipariş sistemlerinde, müşteri en kilit konumundadır. Bu sistemler sayesinde, maliyetlerde düşüş, işlem hızlarında artış, müşteriler adına esneklik sağlanabilmektedir (Applegate vd. 2003, s.83).

\section{Küresel Tedarik Zincirini Etkileyen Faktörler}

Tedarik zinciri yönetiminin tasarımını, karar problemi kapsamında değerlendirecek olursak, ürün tesislerinin sayısı ve lokasyonu kapsamında, her bir tesisin kapasite miktarı, her pazarın diğer bir pazara olan mesafesi ve tedarik seçimini içerir. Küresel tedarik zinciri tasarımı, tesislerin uluslararası lokasyonunu seçmeyi gerektirir ve özel küresel faktörleri içerir. Bu tasarım kararları merkezci olmayabilir, bununla birlikte yöneticiler her tesiste kendi kararını verir ya da merkezci bir yapıda olabilir, kararlar diğer tesislerle karşılaştırılıp koordine edilebilir. Burada esas önemli olan yöneticilerin, işletmenin tedarik zinciri yönetimi stratejisiyle tutarlı kararları seçmeleri ve uygulamalarıdır (Meixell, 2005, s. 531-550).

Küresel piyasalarda tedarik zincirinde yer alan sektörün başarı faktörlerinin tanımlanması, firmaların rekabetçi konumlarının belirlenmesinde önemli bir rol oynar. Bu başarı faktörleri, firmanın rekabetçi performans düzeyini etkilemesi açısından önemi yüksek olan alanları ifade 
etmektedir. Bu alanlardaki kötü sonuçlar, firmanın performansını doğrudan ve kısa sürede olumsuz etkileyecektir. Buna karşın, iyi sonuçlar da performansın artmasını sağlayacaktır.

Dolayısıyla küresel tedarik zincirini etkileyen başarı faktörlerini şu şekilde sıralamak mümkündür;

1. Benzersiz ürün ve hizmet: Bazı ürün ve hizmetlerin tek bir tedarikçisi olmasından dolayı bu tarz bir temin yöntemi tercih edilebilir. Özel talepleri karşılamak için çıkarılan, benzeri daha önce üretilmemiş/yapılmamış ürünler ve hizmetlerdir. Ayrıca bir tek olarak ya da çok özelleştirilmiş olarak üretilen ve belirli bir tüketici kitlesinin özel istek ve gereksinmelerini karşılayan, alıcıların elde etmek için zaman ve para harcamayı göze aldığı ürün ve hizmet türleri de denilebilir (Özdemir, 2004, s.93, Güleş ve Bülbül, 2004, s.135).

2. Çalışanların iş yapma arzusu: Bazı durumlarda yabancı tedarikçiler iş yapma konusunda daha fazla ilgi göstermelerinden ve daha fazla çaba sarf etmelerinden dolayı tercih edilmektedirler. Çalışanların performansı düzenli olarak ölçülmelidir. Bu durum doğrultusunda global tedarik zinciri yönetimi çalışanlarına, etkin ve verimli olmaları için gerekli imkanlar sunulmalı, eğitim verilmeli ve kariyerlerinde yükselme imkanları sağlanmalıdır (Yön, 2007, s.20).

3. Düşükk maliyetler: Uluslararası sınırlarda satın alma işletmeler için daha düşük maliyetli ürün ve hizmet temin etmelerini sağlar bu yabancı tedarikçilerin küresel piyasada yer almalarından dolayı maliyet avantajlarından ya da sahip oldukları kur farklarından kaynaklanabilir (Yön, 2007, s.20, Türköz, 2007, s.22).

4. Üstün kalite: Yurt dışındaki tedarikçiler yurt içindekilere nazaran daha kaliteli ürün sunmalarından dolayı tercih edilebilmektedirler. Pazarda lider olan tedarikçilerin sunduğu kalite garantisi tercih sebebi olmalarına ana bir neden olarak ifade edilebilir. Kalite, sistemli ve düzenli olarak iyileştirilmelidir. Unutmamak gerekir ki, tedarik zinciri yönetimi üstün performansı, en doğru olarak, rakiplerle kıyaslama ve rekabet farkındalığı ile yapılır. Böylece her safhada, yapılmış hatalar düzeltilir, hız artırılır ve para dönüşü etkin olarak sağlanır (Türköz, 2007, s. 21, Yön, 2007, s.20).

5. Uygulama hızı; Tedarik zinciri yönetimi, müşteri taleplerini en verimli ve en kısa sürede karşılamalıdır. Dolayısıyla firmaların yetenekleri; tedarik zincirinde cevap verebilme düzeylerini ve hızlarını belirler. Tedarik zinciri hızını; çalışanların bilgi ve becerileri, talep karşılama yönetimi, tedarik ve üretim yetenekleri, esneklik kapasiteleri ve sürdürülebilirlikleri belirler. Bunları, müşterilerin dinamik talepleriyle beraber ele almak ve değerlendirmek daha doğru olur (Türköz, 2007, s.22, Tokdemir, 2016).

6. Yerel gereklilikleri ve talepleri yerine getirme ihtiyacı: Yerel gereklilik, bir ülkedeki kuruluşun çalışma düzenini, yöntemini belirleyen, bu kuruluşta çalışanların uyacakları kuralları içermektedir. Bu sebeple yabancı bir pazar için üretim yapılıyorsa bu ürünün hedef pazarda daha çekici olmasını sağlamak için ilgili ülkenin yerel gerekliliğine göre tedarikçilerinden temin sağlanabilir (Yön, 2007, s.20).

7. Kapasitenin Artırılması: Etkin ve verimli bir tedarik zinciri yönetiminin temel taslarından biri operasyon yönetimi sisteminin hiçbir zaman girdi yetersizliği ile karşı karşıya kalmamasıdır. Yurt içi tedarikçilerin taleplere yetişemediği durumlarda yabancı 
tedarikçilerden gereken ürünlerin temini kararı verilebilir (Yön, 2007: 20, Kueia, vd, 2011, s.4457-4481).

8. Mevcut pazar taahhütlerini yerine getirme gerekliliği: İşletmeler yabancı işletmelere büyük miktarlarda satış yaptıklarında, satış koşullarının bir parçası olarak işletmenin yine yabancı bir işletmeden ürün ve hizmet satın alarak yatırım yapması ve satış ile ilgili sorumlulukların ilgili firmaya karşı yerine getirilmesi beklenmektedir (Yön, 2007, s.20).

9. Rekabet edebilen bir insan kaynağına sahip nitelikli ve üstün donanımlı bir insan kaynağına sahip olunmalıdır. Yüksek deneyim, bilgi ve beceriye (EQ dahil) sahip insanlarla çalışılmalı ve uygun nitelikleri taşıyan insanlar işe alınmalıdır (Tokdemir, 2016).

10. Etkin ve rekabetçi küresel tedarik zinciri stratejisi, hazırlanmalı ve uygulanmalıdır. Bunun içinde; kısa ve uzun vadede iş, organizasyon, teknoloji, enformasyon ve uygulamalar ile rekabetçi düşük maliyet yapısını getirecek; hızlılık, karşılayabilme, varlık yönetimi ve güvenirlilik olmalıdır (T.C. Ekonomi Bakanlığı, 2014).

11. Yönetmeliklerin titizlikle uygulanması ve ilgili kamu kuruluşları ile etkin iletişimde bulunulması gerekmektedir (Tokdemir, 2016).

12. Etkin bir risk yönetimi ve bilgi yönetim sistemi oluşturulmalı ve uygulanmalıdır. Bunlar etkin bir tedarik zinciri yönetimi ve üretim yönetimi ile ilgili kurumların temel unsurlarıdır (Tokdemir, 2016, Manuj ve Mentzer, 2008, s. 192-223)

13. Etkin bir talep planlama sistemi kurulmalı ve uygulanmalıdır. Yani şirketlerin ürünlerine veya hizmetlerine yönelik talebin miktarını ve zamanlamasını doğru şekilde öngörebilmesi amacıyla gerçekleştirdiği sistematik planlama faaliyetleri gerçekleştirilmelidir. Etkin bir talep planlama ile talebi tüm uçtan uca tedarik zinciri ağ boyunca olabilecek en yüksek olasılıkla ölçme, talep tahminleri ve üretim operasyonlarını optimize edip maliyeti minimuma indiren planlar, firmalara üretme yetkinliğini kazandırabilmektedir (Lambert vd. 2002, s.51-66).

$\mathrm{Bu}$ belirlenen başarı faktörleri, yöneticilerin sürekli izlemesi gereken faaliyet alanlarıdır. Dolayısıyla bu faktörlerin önem düzeyinin belirlenmesi gerekmektedir. Bu faktörlerin önem düzeyini ve önem düzeyi sıralamasını belirlemek için SWARA ve COPELAND yöntemlerinden yararlanılmıştır. Literatürde bu yöntemler kullanılarak küresel tedarik zincirini etkileyen bu kritik başarı faktörlerinin önem düzeyinin ve sıralamasının belirlenmesi ile ilgili herhangi bir çalışmaya rastlanmamıştır. Bu durum, çalışmanın özgünlüğünü göstermektedir.

\section{SWARA Yöntemi}

Kriter ağırlıklandırma yöntemleri arasında yer alan ve son zamanlarda sıklıkla kullanılmaya başlanan SWARA'nın açılımı “Step-Wise Weight Assessment Ratio Analysis” dır ve Türkçe 'de “Adım Adım Ağırlık Değerlendirme Oran Analizi” olarak kullanılabilir (Keršuliene vd. 2010, s. 243-258). 
SWARA yöntemi, mevcut çevresel ve ekonomik durumları dikkate alan karar vericilere kendi önceliklerini seçme konusunda fırsat tanımaktadır. Ayrıca karar verici olarak belirlenen uzmanların değerlendirmeleri bu yöntemde daha da önemlidir. Çoğu karar verici karar verme süreçlerinde çeşitli kriterleri değerlendirirken zorlanmaktadır. Buna ek olarak bazı yöntemlerde hesaplamalar oldukça karmaşı veya kullanılan yöntem yeterince objektif bir yön içermemektedir ve bu yöntemlerin matematiksel model yapılarından dolayı objektif değerlendirmelere da olanak tanımamaktadır. SWARA yönteminde uzman kişiler bilgi birikimlerini ve tecrübelerini kullanabildiklerinden, süreç karmaşık ve zaman alıcı değildir (Zolfani ve Saparauskas, 2013c, s.408-414). Başka bir deyişle bu yöntemin matematiksel olarak hesaplamalarının daha kolay olması ve uzman değerlendirmelerini daha ön plana çıkaracak şekilde modellenmiş olması, kullanılabilirliğini ve uygulanabilirliğini kolaylaştırmaktadır. Uzmanlar karar verme sürecinde birbirlerine danışarak ortak bir karar oluşturabilirler ya da birden fazla uzman ayrı ayrı değerlendirmelerini gerçekleştirebilirler. Uzmanların seçilen kriterlere yönelik sayısal değerlendirmelerinin ortalamaları alındığından bu yöntem uzmanların birlikte çalışmalarını kolaylaştırmaktadır. Ayrıca bu yöntem ile uzmanların kriterler hakkındaki hassasiyet ve duyarlılıklarına tam olarak hakim olunabilmektedir. SWARA yöntemi ile ilgili literatür incelendiğinde Tablo 1'de gösterilen birçok problemin çözümünde kullanıldığı bilgisi ile karşılaşılmıştır.

\section{Tablo 1. SWARA Literatür Taraması}

\begin{tabular}{|ll|}
\hline İLGÍLi YAYIN & ÇÖZÜLEN PROBLEM \\
\hline Keršuliene vd. 2010 & Uyuşmazlık çözümü \\
\hline Keršulienė ve Turskis, 2011 & Mimar seçimi \\
\hline Zolfani vd. 2013a & Mekanik havalandırma alternatifinin seçimi \\
\hline Alimardani vd. 2013 & Tedarikçi seçimi \\
\hline Zolfani vd. 2013b & Ürün tasarımı \\
\hline Aghdaie vd. 2013 & Makine parçası seçimi \\
\hline Zolfani ve Saparauskas, 2013c & Enerjide sürdürülebilirlik göstergelerinin önceliklendirilmesi \\
\hline Zolfani ve Banihashemi, 2014a & Personel seçimi \\
\hline Zolfani ve Bahrami, 2014b & SWARA-COPRAS yaklaşımı ile yatırım önceliklendirme \\
\hline Vafaeipour vd. 2014 & Güneş enerji santrallerinin kurulacağı bölgenin seçimi \\
\hline Aghdaie vd. 2014a & Tedarikçi kümeleme ve sıralama \\
\hline Aghdaie vd. 2014b & Satış şubesi seçimi \\
\hline Dehnavi vd. 2015 & Bölgesel heyelan tehlikesinin değerlendirilmesi \\
\hline Karabasevic vd. 2015 & İşe alınacak maden mühendisi adaylarının seçilmesi \\
\hline Stanujkic vd. 2015a & Personel seçimi \\
\hline Stanujkic, vd. 2015b & Paket tasarımı seçimi \\
\hline Shukla vd. 2016 & ERP sistemi seçimi \\
\hline Yazdani vd. 2016 & Malzeme seçimi \\
\hline Çakır, 2017a & Kriter ağırlıklarının belirlenmesi \\
\hline Juodagalviene vd. 2017 & Konut planı seçimi \\
\hline Çakır ve Karabıyık, 2017b & \\
\hline
\end{tabular}


Tabloda görülen çalışmalar incelendiğinde matematiksel işlemlerin oldukça az ve basit olduğu gözlemlenmiş ve tespit edilmiştir. Yöntemde alternatiflerin değerlendirilmesinde kullanılacak olan kriterler en çok önemliden en az önemsize doğru sıralanmakta ve oylama yapılarak önemsiz kriterler elimine edilmektedir. Kalan kriterlerin önem ağırlıklarını hesaplarken her bir karar vericinin kendisine göre oluşturduğu sıralama dikkate alınmaktadır. SWARA adımları ise aşağıdaki gibidir (Keršuliene vd., 2010, s.243-258):

Adım 1: Her bir karar verici kendisine göre en önemli olan kriteri belirler. Burada en önemli kriter 1,00 puanını alır. Karar vericiler diğer kriterlere puan atamasını en önemli kriteri dikkate alarak yaparlar. Puanlar, 0 ila 1 arasında 2,3,4'ün ve 5’in katları başta olacak şekilde atanır. Kriterlere atanan puanlar, $p_{j}^{k} ; \mathrm{j}=1, \ldots, \mathrm{k}=1, \ldots, l ; 0 \leq p_{j}^{k} \leq 1$ olarak gösterilir.

Adım 2: Tüm kriterler için göreli ortalama önem puanı hesaplanır. $l$ karar verici sayısını göstermek üzere karar vericiler tarafından kriterlere atanan göreli önem puanlarının her bir kriter için ortalaması eşitlik (1) yardımıyla hesaplanır.

$$
\bar{p}_{j}=\frac{\sum_{k=1}^{l} p_{j}^{k}}{l} ; 1, \ldots, n
$$

Adım 3: Tüm kriterler göreli ortalama önem puanlarına göre büyükten küçüğe doğru sıralanarak karşılaştırılır. Bu yapılan karşılaştırma sonucunda ortalama değerin karşılaştırmalı önemi $s_{j}$ değerleri hesaplanır. $c_{j}$ değerleri $j+1$ kriterinin $j$ kriterine göre ne kadar önemli olduğunu gösterir ve ikili kıyaslama yoluyla elde edilir.

Adım 4: Tüm kriterler için katsayı değeri $c_{j}$, Eşitlik (2) kullanılarak hesaplanır. En büyük $s_{j}$ değerine sahip kritere ait katsayı $c_{j}=1$ değerini almaktadır.

$$
c_{j}=s_{j}+1 ; j=1, \ldots, n
$$

Adım 5: Tüm kriterler için düzeltilmiş ağırlıklar ( $\left.s_{j}^{\prime}\right)$ Eşitlik (3) yardımıyla hesaplanır. Birinci sırada yer alan kriterin düzeltilmiş ağırlığ $1 s_{j}^{\prime}=1$ 'dir.

$$
s_{j}^{\prime}=\frac{s_{j-1}^{\prime}}{c_{j}}
$$

Adım 6: Tüm kriterler için Eşitlik (4) yardımıyla nihai ağırlıklar $\left(w_{j}\right)$ hesaplanır.

$$
w_{j}=\frac{s_{j^{\prime}}}{\sum_{j=1}^{n} s_{j^{\prime}}}
$$




\section{COPELAND Yöntemi}

Alternatifler arasından seçim yapmada Condorcet ilkelerinin kullanıldı̆̆ı Copeland yönteminde bir alternatifin diğer alternatiflere galip gelme ve mağlup olma sayılarının farkı alınır ve elde edilen skorlar ile alternatifler en iyiden başlamak üzere sıralanır(Sanver, 2000, s. 133-144). Copeland adımları aşağıdaki gibidir.(Browne, 2013, Fishburn, 1977, s 469-489, Klamler, 2003, s.1-7):

Adım 1: Copeland yönteminde ilk adım alternatifler arasında ikili karşılaştırmalar yapmaktır. Her bir $f_{k}(i, j)$ değerine, $A_{\mathrm{I}}$ ve $A_{j}$ alternatifleri karşılaştırmasında $A i$ alternatifi galip gelmiş ise (diğer ifadeyle sıralamada üstte ise) ' 1 '; $A_{J}$ alternatifi galip gelmiş ise ' 0 ' vermektir. Bu ifadeler $f_{k}(i, j)=\{0,1\}$ olmak üzere eşitlik (5)'de gösterilebilir.

$$
f_{k}(i, j)=\left\{\begin{array}{llll}
1 & r_{k}\left(A_{\mathrm{I}}\right)<r_{k}\left(A_{j}\right) & \text { ve } & i \neq j \\
0 & r_{k}\left(A_{\mathrm{I}}\right)>r_{k}\left(A_{j}\right) & \text { ve } & i \neq j \\
\text { boș }(-) & r_{k}\left(A_{\mathrm{I}}\right)=r_{k}\left(A_{j}\right) & \text { veya } & i=j
\end{array}\right.
$$

Adım 2: Bu adımda karar verici bazında skorlar hesaplanmaktadır. $S(i, j), A_{i}$ alternatifinin $A_{j}$ alternatifine göre her bir karar vericiden elde ettiği toplam oy sayısını göstermektedir. Böylece, eşitlik (6) ile $i$. alternatifin $j$. alternatife göre aldığı oy sayısı bulunur.

$$
s(i, j)=\sum_{k=1}^{m} f_{k}(i, j) \quad \text { ve } i \neq j
$$

Adım 3: Elde edilen $S(i, j)$ yardımıyla alternatifler arasındaki karşılaştırmada, galipler bulunacaktır. Bunun için eşitlik (7)'den yararlanılacaktır. Eşitliğe bakıldığında galip gelen taraf “1” puan, yenilen taraf “-1" puan almaktadır. Eşitlik durumunda ise "1/2" puan verilmektedir.

$$
G(i, j)=\left\{\begin{array}{lll}
1 & S(i, j)>(m-S(i, j)) & i \neq j \\
\frac{1}{2} & S(i, j)=(m-S(i, j)) & i \neq j \\
-1 & S(i, j)<(m-S(i, j)) & i \neq j
\end{array}\right.
$$

Adım 4: Elde edilen 1 ve $1 / 2$ puanlarına sahip $G(i, j)$ değerleri alternatifler bazında toplanarak galibiyet puanına $\left(G P_{i}\right)$; -1 puana sahip $G(i, j)$ değerleri toplanarak alternatifin yenilgi puanına $\left(Y P_{i}\right)$ ulaşılır. Bunun için eşitlik (8) ve (9)'dan yararlanılır.

$$
\begin{array}{rr}
G P_{\mathrm{I}}=\sum_{i=1}^{n} G(i, j) & G(i, j)>0 \\
Y P_{i}=\sum_{i=1}^{n} G(i, j) & G(i, j)<0
\end{array}
$$

Elde edilen $G P_{i}$ ve $Y P_{i}$ değerlerinin toplanması sonucu Copeland Puanına $\left(C P_{i}\right)$ ulaşılır. Tablo 12 'de, alternatiflerin $G P_{i}, Y P_{i}$ ve $C P_{i}$ değerlerini göstermektedir.

$$
C P_{i}=G P_{\mathrm{I}}+Y P_{i}
$$

Adım 5: Copeland puanı yüksek olanın en iyi olduğu sonucundan hareketle; alternatifler, elde edilen Copeland puanlarına göre sıralanır. Copeland puanları arasında eşitlik söz konusu olursa, i değeri küçük olan sıralamada üstte yer alacaktır. 


\section{Uygulama}

SWARA yöntemi sürece birden çok karar verici katılırsa, ölçütleri önem sırasına göre azalan düzeyde sıralamaya olanak tanımaktadır. Dolayısıyla, bu yöntem ile teorik olarak ölçütlerin tek karar vericiye göre değerlendirilmesi mümkün olsa da, uygulamada sürece birden çok karar vericinin katıldığı durumlar dikkate alınmaktadır. Dolayısıyla, bu çalışmada, karar verici sayısı 4 olduğu için, karar verici sayısı analizler için yeterlidir (Zolfani vd.2013b, s.158)

Kocaeli'nde faaliyet gösteren bir otomotiv işletmesinin çalıştığ şirketinin yönetimini etkileyen kritik başarı faktörlerinin önem düzeyinin belirlenmesi için SWARA ve COPELAND yöntemleri yardımıyla uygulama yapılmıştır. Öncelikle lojistik departmanında görev yapan bir Tedarikçi Kalite Mühendisi, Tedarikçi Geliştirme Uzmanı ve iki tane Tedarik Uzmanı olmak üzere toplam dört karar vericiye $\left(\mathrm{KV}_{1}, \mathrm{KV}_{2}, \mathrm{KV}_{3}, \mathrm{KV}_{4}\right)$ Ek'te yer alan anket uygulanmıştır.

Ankette 13 faktör $\left(\mathrm{K}_{1}, \mathrm{~K}_{2}, \mathrm{~K}_{3}, \ldots \mathrm{K}_{13}\right)$ detaylı bir literatür taraması ile belirlenmiştir. Bu formda belirtilen kriterleri, karar vericilerin uygun gördükleri şekilde önem derecesine göre sıralandırmaları ve puanlandırmaları istenmiştir.

Adım 1: Öncelikle, karar vericilerin faktörleri 1'den 13'e kadar sıralamaları istenmiştir. Doldurdukları anketlerde belirtmiş oldukları önem sırasına göre Tablo 2'de görülen sıralama tablosu oluşturulmuştur.

Tablo 2. Karar Vericiler (KV) Düzeyinde Kriter Stralama

\begin{tabular}{llcccc}
\hline & & $\mathbf{K V}_{\mathbf{1}}$ & $\mathbf{K V}_{\mathbf{2}}$ & $\mathbf{K V}_{\mathbf{3}}$ & $\mathbf{K V}_{\mathbf{4}}$ \\
\hline $\boldsymbol{K}_{\mathbf{1}}$ & Benzersiz ürün ve hizmet & 5 & 3 & 2 & 3 \\
$\boldsymbol{K}_{\mathbf{2}}$ & Çalışanların iş yapma arzusu & 4 & 5 & 5 & 5 \\
$\boldsymbol{K}_{\mathbf{3}}$ & Düşük maliyetler & 2 & 4 & 4 & 4 \\
$\boldsymbol{K}_{\mathbf{4}}$ & Üstün kalite & 3 & 1 & 3 & 2 \\
$\boldsymbol{K}_{\mathbf{5}}$ & Uygulama hızı & 1 & 2 & 1 & 1 \\
$\boldsymbol{K}_{\mathbf{6}}$ & Yerel gereklilikleri ve talepleri yerine getirme ihtiyacı & 7 & 8 & 9 & 8 \\
$\boldsymbol{K}_{\mathbf{7}}$ & Kapasitenin Artırılması & 8 & 6 & 7 & 6 \\
$\boldsymbol{K}_{\mathbf{8}}$ & Mevcut pazar taahhütlerini yerine getirme gerekliliği & 13 & 10 & 12 & 10 \\
$\boldsymbol{K}_{\mathbf{9}}$ & Rekabetçi Bir İnsan Kaynağına Sahip Olunması & 6 & 7 & 6 & 7 \\
$\boldsymbol{K}_{\mathbf{1 0}}$ & Etkin ve rekabetçi küresel tedarik zinciri stratejisi & 10 & 9 & 8 & 9 \\
$\boldsymbol{K}_{\mathbf{1 1}}$ & Yönetmelikler & 12 & 13 & 11 & 13 \\
$\boldsymbol{K}_{\mathbf{1 2}}$ & Etkin bir risk yönetimi ve bilgi yönetim sistemi & 11 & 12 & 13 & 11 \\
$\boldsymbol{K}_{\mathbf{1 3}}$ & Etkin bir talep planlama sistemi & 9 & 11 & 10 & 12 \\
\hline
\end{tabular}

Daha sonra karar vericiler en önemli kritere 1,00 puanını atamışlar ve diğer kriterlere puan atarken yaptıkları sıralamaya uygun ve tutarlı davranmışlardır. Karar vericilerin kriterlere puan atamaları sonucu $p_{j k}$ değerlerinden oluşan Tablo 3 'te elde edilmiştir. 
Tablo 3. Karar Vericiler (KV) düzeyinde Kriterlerin Önem Derecesine Göre Puanlandırılması ( $p_{j k}$ değerleri)

\begin{tabular}{llllll}
\hline & & $\mathbf{K V}_{\mathbf{1}}$ & $\mathbf{K V}_{\mathbf{2}}$ & $\mathbf{K V}_{\mathbf{3}}$ & $\mathbf{K V}_{\mathbf{4}}$ \\
\hline $\boldsymbol{K}_{\mathbf{1}}$ & Benzersiz ürün ve hizmet & 0.80 & 0.85 & 0.95 & 0.85 \\
$\boldsymbol{K}_{\mathbf{2}}$ & Çalışanların iş yapma arzusu & 0.85 & 0.75 & 0.85 & 0.70 \\
$\boldsymbol{K}_{\mathbf{3}}$ & Düşük maliyetler & 0.95 & 0.80 & 0.80 & 0.80 \\
$\boldsymbol{K}_{\mathbf{4}}$ & Üstün kalite & 0.90 & 1.00 & 0.90 & 0.95 \\
$\boldsymbol{K}_{\mathbf{5}}$ & Uygulama hızı & 1.00 & 0.95 & 1.00 & 1.00 \\
$\boldsymbol{K}_{\mathbf{6}}$ & Yerel gereklilikleri ve talepleri yerine getirme ihtiyacı & 0.60 & 0.50 & 0.60 & 0.55 \\
$\boldsymbol{K}_{\mathbf{7}}$ & Kapasitenin Artırlması & 0.55 & 0.70 & 0.70 & 0.65 \\
$\boldsymbol{K}_{\mathbf{8}}$ & Mevcut pazar taahhütlerini yerine getirme gerekliliği & 0.15 & 0.35 & 0.20 & 0.40 \\
$\boldsymbol{K}_{\mathbf{9}}$ & Rekabetçi Bir İnsan Kaynağına Sahip Olunması & 0.70 & 0.65 & 0.75 & 0.60 \\
$\boldsymbol{K}_{\mathbf{1 0}}$ & Etkin ve rekabetçi küresel tedarik zinciri stratejisi & 0.40 & 0.45 & 0.65 & 0.50 \\
$\boldsymbol{K}_{\mathbf{1 1}}$ & Yönetmelikler & 0.20 & 0.10 & 0.30 & 0.10 \\
$\boldsymbol{K}_{\mathbf{1 2}}$ & Etkin bir risk yönetimi ve bilgi yönetim sistemi & 0.35 & 0.20 & 0.15 & 0.30 \\
$\boldsymbol{K}_{\mathbf{1 3}}$ & Etkin bir talep planlama sistemi & 0.45 & 0.25 & 0.40 & 0.20 \\
\hline
\end{tabular}

Adım 2: Tüm kriterler için göreli ortalama önem puanı $\left(\bar{p}_{j}\right)$ Eşitlik (1) yardımıyla hesaplanmıştır. Elde edilen sonuçlar tablosu Tablo 4’te görülmektedir.

Tablo 4. Kriterler için Ortalama Önem Puanları

\begin{tabular}{cc}
\hline KRİTERLER & Ortalama Önem Puanları $\left(\overline{\boldsymbol{p}}_{\boldsymbol{j}}\right)$ \\
\hline $\boldsymbol{K}_{\mathbf{1}}$ & 0,86 \\
$\boldsymbol{K}_{\mathbf{2}}$ & 0,79 \\
$\boldsymbol{K}_{\mathbf{3}}$ & 0,84 \\
$\boldsymbol{K}_{\mathbf{4}}$ & 0,94 \\
$\boldsymbol{K}_{\mathbf{5}}$ & 0,99 \\
$\boldsymbol{K}_{\mathbf{6}}$ & 0,56 \\
$\boldsymbol{K}_{\mathbf{7}}$ & 0,65 \\
$\boldsymbol{K}_{\mathbf{8}}$ & 0,28 \\
$\boldsymbol{K}_{\mathbf{9}}$ & 0,68 \\
$\boldsymbol{K}_{\mathbf{1 0}}$ & 0,50 \\
$\boldsymbol{K}_{\mathbf{1 1}}$ & 0,18 \\
$\boldsymbol{K}_{\mathbf{1 2}}$ & 0,25 \\
$\boldsymbol{K}_{\mathbf{1 3}}$ & 0,33 \\
\hline
\end{tabular}

Adım 3: Tüm kriterler ortalama önem puanlarına göre büyükten küçüğe doğru sıralanarak, kriterler için ortalama değerin karşılaştırmalı önemi $\left(s_{j}\right)$ değerleri tablosu Tablo 5 'de görüldüğü gibi hesaplanmıştır. Kriterlerin önem sıralaması $\mathrm{K} 5>\mathrm{K} 4>\mathrm{K} 1>\mathrm{K} 3>\mathrm{K} 2>\mathrm{K} 9>\mathrm{K} 7>\mathrm{K} 6>\mathrm{K} 10>\mathrm{K} 13>\mathrm{K} 8>\mathrm{K} 12>\mathrm{K} 11$ şeklinde elde edilmiştir. 
Tablo 5. Kriterler için Ortalama Önem Puanlarının Karşılaştırılması

\begin{tabular}{lcc}
\hline Kriterler & $\begin{array}{c}\text { Ortalama Önem } \\
\text { Puanları }\left(\boldsymbol{p}_{\boldsymbol{j}}\right)\end{array}$ & $\begin{array}{c}\text { Ortalama Değerin } \\
\text { Karşılaştırmalı Önemi }\left(s_{j}\right)\end{array}$ \\
\hline $\boldsymbol{K}_{\mathbf{5}}$ & 0,99 & 0,05 \\
$\boldsymbol{K}_{\mathbf{4}}$ & 0,94 & 0,08 \\
$\boldsymbol{K}_{\mathbf{1}}$ & 0,86 & 0,02 \\
$\boldsymbol{K}_{\mathbf{3}}$ & 0,84 & 0,05 \\
$\boldsymbol{K}_{\mathbf{2}}$ & 0,79 & 0,11 \\
$\boldsymbol{K}_{\mathbf{9}}$ & 0,68 & 0,03 \\
$\boldsymbol{K}_{\mathbf{7}}$ & 0,65 & 0,09 \\
$\boldsymbol{K}_{\mathbf{6}}$ & 0,56 & 0,06 \\
$\boldsymbol{K}_{\mathbf{1 0}}$ & 0,5 & 0,17 \\
$\boldsymbol{K}_{\mathbf{1 3}}$ & 0,33 & 0,05 \\
$\boldsymbol{K}_{\mathbf{8}}$ & 0,28 & 0,03 \\
$\boldsymbol{K}_{\mathbf{1 2}}$ & 0,25 & 0,07 \\
$\boldsymbol{K}_{\mathbf{1 1}}$ & 0,18 & \\
\hline
\end{tabular}

Adım 4: Tüm kriterler için katsayı değeri $\left(c_{j}\right)$, Eşitlik (2) kullanılarak hesaplanmıştır. Elde edilen değerler tablosu Tablo 6’da görülmektedir.

Tablo 6. Kriterlere ait Katsayı $\left(c_{j}\right)$ Değerleri

\begin{tabular}{cc}
\hline Kriterler & Katsayı Değerleri $\left(\mathrm{C}_{\mathrm{j}}\right)$ \\
\hline $\boldsymbol{K}_{\mathbf{5}}$ & 1 \\
$\boldsymbol{K}_{\mathbf{4}}$ & 1,05 \\
$\boldsymbol{K}_{\mathbf{1}}$ & 1,08 \\
$\boldsymbol{K}_{\mathbf{3}}$ & 1,02 \\
$\boldsymbol{K}_{\mathbf{2}}$ & 1,05 \\
$\boldsymbol{K}_{\mathbf{9}}$ & 1,11 \\
$\boldsymbol{K}_{\mathbf{7}}$ & 1,03 \\
$\boldsymbol{K}_{\mathbf{6}}$ & 1,09 \\
$\boldsymbol{K}_{\mathbf{1 0}}$ & 1,06 \\
$\boldsymbol{K}_{\mathbf{1 3}}$ & 1,17 \\
$\boldsymbol{K}_{\mathbf{8}}$ & 1,05 \\
$\boldsymbol{K}_{\mathbf{1 2}}$ & 1,03 \\
$\boldsymbol{K}_{\mathbf{1 1}}$ & 1,07 \\
\hline
\end{tabular}

Adım 5: Tüm kriterler için düzeltilmiş ağırlıklar $\left(s_{j}^{\prime}\right)$, Eşitlik (3) yardımıyla hesaplanarak elde edilen değerler tablosu Tablo 7 'de görülmektedir. Burada, birinci sirada yer alan kriterin düzeltilmiş ağırlığ $1\left(s_{j}^{\prime}\right)=1$ 'dir. 
Tablo7. Kriterlere ait Düzeltilmiş Ăğırlık Değerleri $\left(s_{j}^{\prime}\right)$

\begin{tabular}{cc}
\hline Kriterler & DÜZELTiLMiş AĞIRLIK DEĞERLERİ \\
\hline $\boldsymbol{K}_{\mathbf{5}}$ & 1 \\
$\boldsymbol{K}_{\mathbf{4}}$ & 0,95 \\
$\boldsymbol{K}_{\mathbf{1}}$ & 0,88 \\
$\boldsymbol{K}_{\mathbf{3}}$ & 0,86 \\
$\boldsymbol{K}_{\mathbf{2}}$ & 0,82 \\
$\boldsymbol{K}_{\mathbf{9}}$ & 0,74 \\
$\boldsymbol{K}_{\mathbf{7}}$ & 0,72 \\
$\boldsymbol{K}_{\mathbf{6}}$ & 0,66 \\
$\boldsymbol{K}_{\mathbf{1 0}}$ & 0,62 \\
$\boldsymbol{K}_{\mathbf{1 3}}$ & 0,53 \\
$\boldsymbol{K}_{\mathbf{8}}$ & 0,51 \\
$\boldsymbol{K}_{\mathbf{1 2}}$ & 0,49 \\
$\boldsymbol{K}_{\mathbf{1 1}}$ & 0,46 \\
Toplam & $\mathbf{9 , 2 6}$ \\
\hline
\end{tabular}

Adım 6: Tüm kriterler için nihai ağırlıkları Eşitlik (4) kullanılarak hesaplanmıştır. Elde edilen bu ağırlıklar değeri tablosu Tablo 8'de görülmektedir. Buna göre en önemli kriter $\mathrm{K}_{5}$, en az önemli $\mathrm{K}_{11}$ 'dir.

Tablo 8. Kriterlere ait Nihai Ăğırlık $\left(w_{j}^{\prime}\right)$ Değerleri

\begin{tabular}{cc}
\hline Kriterler & NİHȦं AĞIRLIKLAR \\
\hline $\boldsymbol{K}_{\mathbf{5}}$ & 0,108 \\
$\boldsymbol{K}_{\mathbf{4}}$ & 0,103 \\
$\boldsymbol{K}_{\mathbf{1}}$ & 0,095 \\
$\boldsymbol{K}_{\mathbf{3}}$ & 0,093 \\
$\boldsymbol{K}_{\mathbf{2}}$ & 0,089 \\
$\boldsymbol{K}_{\mathbf{9}}$ & 0,080 \\
$\boldsymbol{K}_{\mathbf{7}}$ & 0,078 \\
$\boldsymbol{K}_{\mathbf{6}}$ & 0,071 \\
$\boldsymbol{K}_{\mathbf{1 0}}$ & 0,067 \\
$\boldsymbol{K}_{\mathbf{1 3}}$ & 0,058 \\
$\boldsymbol{K}_{\mathbf{8}}$ & 0,055 \\
$\boldsymbol{K}_{\mathbf{1 2}}$ & 0,053 \\
$\boldsymbol{K}_{\mathbf{1 1}}$ & 0,050 \\
\hline
\end{tabular}

SWARA yöntemi ile kriter ağırlıkları hesaplandıktan sonra, belirlenen ağırlık değerlerinden dolayı oluşan sıralamanın sağlamasının yapılması için COPELAND yöntemi kullanılmıştır. COPELAND yönteminin adımları aşağıdaki gibidir.

Adım 1: Copeland yönteminde ilk adım alternatifler arasında ikili karşılaştırmalar yapmaktır. her bir $f_{k}(i, j)$ değerine, $A_{\mathrm{I}}$ ve $A_{j}$ alternatifleri karşılaştırmasında $A i$ alternatifi galip gelmiş ise (diğer ifadeyle sıralamada üstte ise) ' 1 '; $A_{J}$ alternatifi galip gelmiş ise ' 0 ' vermektir. 


\section{Tablo 9. Copeland İkili Karşılaştırma Matrisi (Excel Çözümü)}

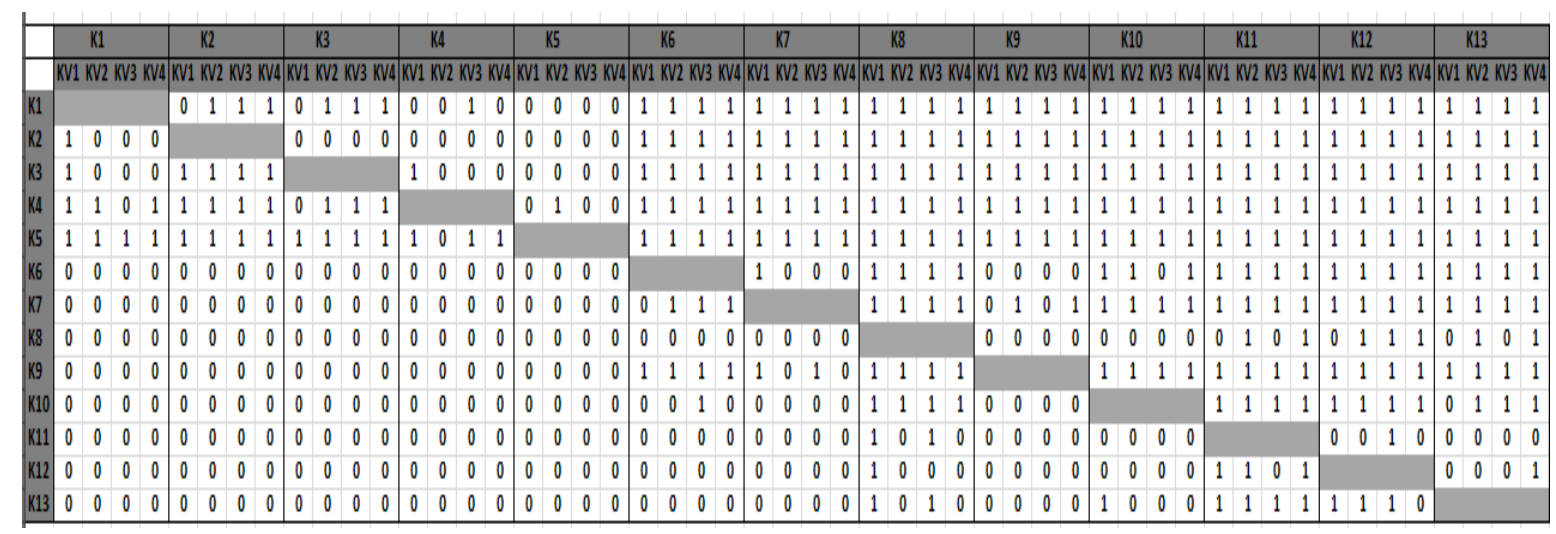

Yani Tablo 9'da görüldüğü üzere karar vericilerin 13 kriter için yaptıkları sıralama dikkate alınarak bir matris oluşturulmuştur. Bu matris oluşturulurken bir karar vericinin bir kriter için belirlediği sıralama diğer bir kriter için belirlediği sıralamadan yüksek ise ilgili değer 0, düşük ise 1 değerini alır. Örneğin yukarıdaki tabloda $\mathrm{KV}_{1}$ için, $\mathrm{K}_{1}$ 'i 5., $\mathrm{K}_{2}$ 'yi ise 4.olarak belirlemiştir ve $5>4$ olduğu için $\mathrm{K}_{2}$ sütunundaki $\mathrm{KV}_{1}-\mathrm{K}_{1}, 0$ değerini alır. Bu şekilde de diğer tüm hesaplamalar yapılmıştır.

Adım 2: $S(i, j), A i$ alternatifinin $A_{j}$ alternatifine göre her bir karar vericiden elde edilen toplam oy sayısı hesaplanmıştır. Kriterlerin kıyaslamasını içeren toplam değerler tablosu Tablo 10'da gösterilmektedir. Bu değerler eşitlik (6) yardımıyla hesaplanmıştır.

Tablo 10. Alternatifler Arası Oy Sayım Sonuçları

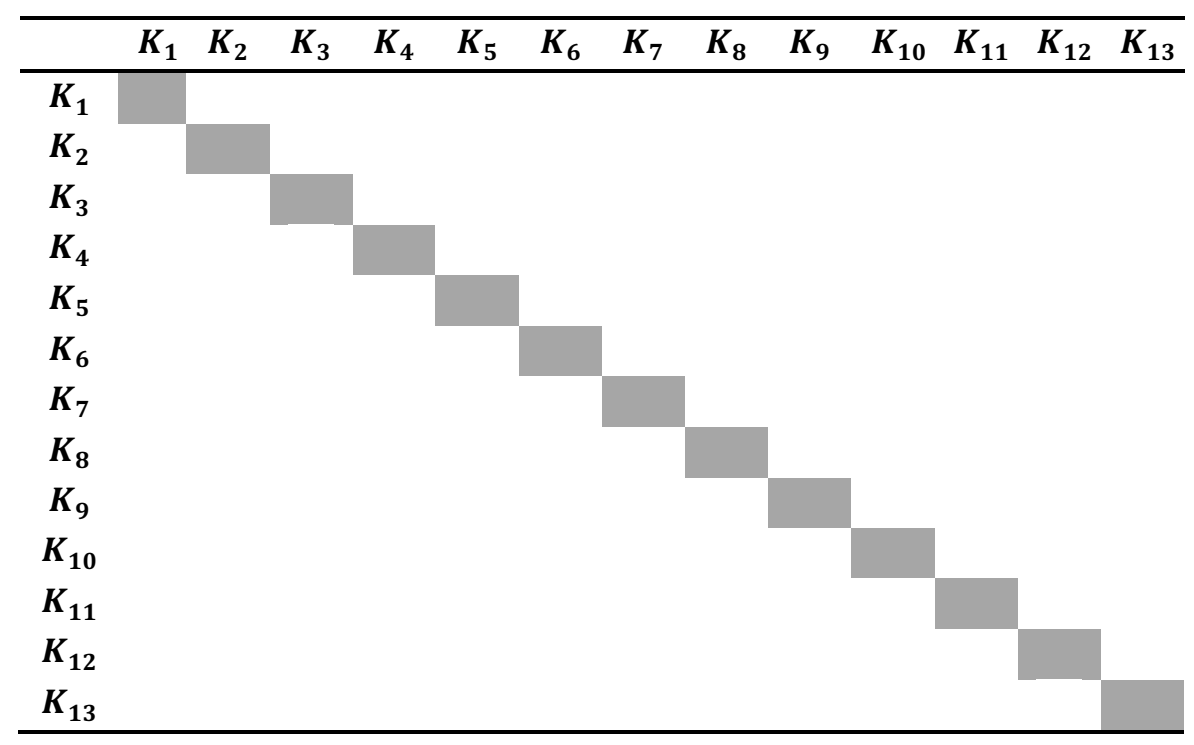

Yukarıdaki Tablo 10'da kriterlerin kıyaslamasını içeren toplam değerler hesaplanmıştır.. Örneğin $K_{1}-K_{2}$ için $K_{1}$ için $K_{1}$ 5., $K_{2}$ ise 4 .sırada idi. $5>4$ olduğu için 0 olur. $K_{2}$ için $K_{1} 3 . K_{2}$ ise 5.sırada idi. $3<5$ olduğu için 1 olur. $\mathrm{KV}_{3}$ için $\mathrm{K}_{1} 2$., $\mathrm{K}_{2}$ ise 5.sırada idi. $2<5$ olduğu için 1 olur. Ve son olarak $\mathrm{KV}_{4}$ için $\mathrm{K}_{1} 3 . \mathrm{K}_{2}$ ise 5. sırada idi. $3<5$ olduğu için 1 olur. $\mathrm{Bu} 4$ değeri toplarsak $0+1+1+1=3$ olur. $K_{1}-K_{2}$ değeri 3 olarak hesaplanır. 
Adım 3: Alternatifler arasındaki galibiyet, yenilgi ve beraberlik durumunu gösteren matris eşitlik (7) yardımıyla hesaplanmış ve tablosu Tablo 11'de gösterilmiştir. Yani bu çalışmaya 4 kişi katıldığı için herhangi iki kriter arasındaki sıralama ile ilgili aslında 4 adet karar var demektir. Bunlar $K_{1}$ için $K_{1}-K_{2}$ sıralaması, $K_{2}$ için $K_{1}-K_{2}$ sıralaması, $K_{3}$ için $K_{1}-K_{2}$ sıralaması ve son olarak $\mathrm{KV}_{4}$ için $\mathrm{K}_{1}-\mathrm{K}_{2}$ sıralamasıdır. Yukarıda hesaplanan 3 değeri 4 değerlendirmenin 3'unde $\mathrm{K}_{1}-\mathrm{K}_{2}$ 'den daha ön sırada önemli olduğunu göstermektedir. Dolayısıyla eğer iki kriter arasındaki kıyaslamaların çoğunda ilgili kriter ön sırada ise buna copeland yöntemine göre galibiyet denir. Burada tüm kriter kıyaslamalarında 4 değerlendirme olacağ iç̧in bir kriter diğer kritere 3 ya da 4 kez daha öncelikli ise galibiyet 1 puan ile, 1 ya da 0 kez önde ise -1 ile, 2 kez üstün ise beraberlik $1 / 2$ ile ifade edilir. Örneğin çizelge 16 'daki matristen yola çıarak $K_{1}-K_{2}, 3$ olduğu için buradaki durum 1 galibiyet puanı ile elde edilir. $\mathrm{K}_{2}-\mathrm{K}_{1}, 1$ olduğu için o da $-1 \mathrm{~K}_{8}-\mathrm{K}_{11}$ ise 2 ile beraberlik $1 / 2$ puan ile ifade edilir.

\section{Tablo 11. Galibiyet - Yenilgi ve Beraberlik Matrisi}

\begin{tabular}{lccccccccccccc}
\hline & $\mathbf{K}_{1}$ & $\mathbf{K}_{2}$ & $\mathbf{K}_{3}$ & $\mathbf{K}_{4}$ & $\mathbf{K}_{5}$ & $\mathbf{K}_{\mathbf{6}}$ & $\mathbf{K}_{\mathbf{7}}$ & $\mathbf{K}_{8}$ & $\mathbf{K}_{\mathbf{9}}$ & $\mathbf{K}_{\mathbf{1 0}}$ & $\mathbf{K}_{\mathbf{1 1}}$ & $\mathbf{K}_{\mathbf{1 2}}$ & $\mathbf{K}_{\mathbf{1 3}}$ \\
\hline $\mathbf{K}_{\mathbf{1}}$ & & 1 & 1 & -1 & -1 & 1 & 1 & 1 & 1 & 1 & 1 & 1 & 1 \\
$\mathbf{K}_{2}$ & -1 & & -1 & -1 & -1 & 1 & 1 & 1 & 1 & 1 & 1 & 1 & 1 \\
$\mathbf{K}_{3}$ & -1 & 1 & & -1 & -1 & 1 & 1 & 1 & 1 & 1 & 1 & 1 & 1 \\
$\mathbf{K}_{4}$ & 1 & 1 & 1 & & -1 & 1 & 1 & 1 & 1 & 1 & 1 & 1 & 1 \\
$\mathbf{K}_{5}$ & 1 & 1 & 1 & 1 & & 1 & 1 & 1 & 1 & 1 & 1 & 1 & 1 \\
$\mathbf{K}_{\mathbf{6}}$ & -1 & -1 & -1 & -1 & -1 & & -1 & 1 & -1 & 1 & 1 & 1 & 1 \\
$\mathbf{K}_{7}$ & -1 & -1 & -1 & -1 & -1 & 1 & & 1 & 0,5 & 1 & 1 & 1 & 1 \\
$\mathbf{K}_{8}$ & -1 & -1 & -1 & -1 & -1 & -1 & -1 & & -1 & -1 & 0,5 & 1 & 0,5 \\
$\mathbf{K}_{9}$ & -1 & -1 & -1 & -1 & -1 & 1 & 0,5 & 1 & & 1 & 1 & 1 & 1 \\
$\mathbf{K}_{10}$ & -1 & -1 & -1 & -1 & -1 & -1 & -1 & 1 & -1 & & 1 & 1 & 1 \\
$\mathbf{K}_{11}$ & -1 & -1 & -1 & -1 & -1 & -1 & -1 & 0,5 & -1 & -1 & & -1 & -1 \\
$\mathbf{K}_{\mathbf{1 2}}$ & -1 & -1 & -1 & -1 & -1 & -1 & -1 & -1 & -1 & -1 & 1 & & -1 \\
$\mathbf{K}_{13}$ & -1 & -1 & -1 & -1 & -1 & -1 & -1 & 0,5 & -1 & -1 & 1 & 1 & \\
\hline
\end{tabular}

Adım 4: Galibiyet ,yenilgi ve Copeland puanları eşitlik $(8,9,10)$ yardımıyla hesaplanmıştır. Alternatiflerin $G P_{i}, Y P_{i}$ ve $C P_{i}$ değerler tablosu Tablo 12' de gösterilmektedir. Buradaki aşamada her kriter için beraberlik ve galibiyet puanları toplanmıştır. (1'ler ve 1/2'ler) Yenilgi puanları ise (-1'ler toplanır), ve galibiyet puanları ile yenilgi puanlarının toplamı copeland puanı olarak hesaplanır. Örneğin $K_{1}$ için galibiyet puanı 10, yenilgi puanı -2 hesaplanmış, toplamı da copeland puanı olarak 10-2=8 olarak hesaplanmıştır. 
Tablo 12. Galibiyet - Yenilgi ve Copeland Puanları

\begin{tabular}{cccc}
\hline KRİTERLER & $\begin{array}{c}\text { GALiBiYYET } \\
\text { PUANI }\end{array}$ & $\begin{array}{c}\text { YENiLGI } \\
\text { PUANI }\end{array}$ & $\begin{array}{c}\text { COPELAND } \\
\text { PUANI }\end{array}$ \\
\hline $\boldsymbol{K}_{\mathbf{1}}$ & 10 & -2 & 8 \\
$\boldsymbol{K}_{\mathbf{2}}$ & 8 & -4 & 4 \\
$\boldsymbol{K}_{\mathbf{3}}$ & 9 & -3 & 6 \\
$\boldsymbol{K}_{\mathbf{4}}$ & 11 & -1 & 10 \\
$\boldsymbol{K}_{\mathbf{5}}$ & 12 & 0 & 12 \\
$\boldsymbol{K}_{\mathbf{6}}$ & 5 & -7 & -2 \\
$\boldsymbol{K}_{\mathbf{7}}$ & 6,5 & -5 & 1,5 \\
$\boldsymbol{K}_{\mathbf{8}}$ & 2 & -9 & -7 \\
$\boldsymbol{K}_{\mathbf{9}}$ & 6,5 & -5 & 1,5 \\
$\boldsymbol{K}_{\mathbf{1 0}}$ & 4 & -8 & -4 \\
$\boldsymbol{K}_{\mathbf{1 1}}$ & 0,5 & -11 & $-10,5$ \\
$\boldsymbol{K}_{\mathbf{1 2}}$ & 1 & -11 & -10 \\
$\boldsymbol{K}_{\mathbf{1 3}}$ & 2,5 & -9 & $-6,5$ \\
\hline
\end{tabular}

Adım 5: Alternatifler, elde edilen Copeland puanlarına göre sıralanır. Kriterlerin sıralaması $\mathrm{K}_{5}>\mathrm{K}_{4}>\mathrm{K}_{1}>\mathrm{K}_{3}>\mathrm{K}_{2}>\mathrm{K}_{7}>\mathrm{K}_{9}>\mathrm{K}_{6}>\mathrm{K}_{10}>\mathrm{K}_{13}>\mathrm{K}_{8}>\mathrm{K}_{12}>\mathrm{K}_{11}$ elde edilmiş ve tablosu Tablo 13'te gösterilmiştir. ( $\mathrm{K}_{7}, \mathrm{~K}_{9}$ 'dan küçük indisli olduğu için büyük olarak kabul edilmiştir.)

Tablo 13. Alternatiflerin Copeland Puanlarına Göre Siralanması

\begin{tabular}{cc}
\hline $\begin{array}{c}\text { Copeland } \\
\text { Puanı }\end{array}$ & Siralama \\
\hline 12 & $K_{5}$ \\
10 & $K_{4}$ \\
8 & $K_{1}$ \\
6 & $K_{3}$ \\
4 & $K_{2}$ \\
1,5 & $K_{7}$ \\
1,5 & $K_{9}$ \\
-2 & $K_{6}$ \\
-4 & $K_{10}$ \\
$-6,5$ & $K_{13}$ \\
-7 & $K_{8}$ \\
-10 & $K_{12}$ \\
$-10,5$ & $K_{11}$ \\
\hline
\end{tabular}

\section{Sonuç}

SWARA yönteminde karar vericilerin her biri belirlenen kriterleri çok farklı ya da birbirine yakın bir şekilde sıralama yapabilir. Bu durumun sağlamasının yapılması için COPELAND yönteminin uygulanması gerekli olabilmektedir. Dolayısıyla SWARA yönteminde 5 adımda elde edilen sıralamaya yakın ya da aynı sıralama COPELAND yöntemi ile de elde edilmişse, o zaman kriterlerin önem düzeyi için oluşan değerlendirmeler geçerli olacaktır. 
Bu çalışma Kocaeli'nde faaliyet gösteren bir otomotiv işletmesinin çalıştığı bir global tedarik zinciri şirketine uygulanmıştır. Bu global tedarik şirketi, otomotiv firmasının nihai ürünlerini yapması için gerekli malzeme, parça ve hizmetlerin sağlanması konusunda görev yapmaktadır. Burada GTZY'yi etkileyen kritik başarı faktörlerinin önem düzeyinin belirlenmesi amaçlanmıştır. Detaylı bir literatür taraması ile 13 faktör belirlenmiştir. Çalışmada öncelikle karar vericiler, bu faktörleri en önemlisi ilk sırada olacak şekilde sıralamalarını yapmıştır. SWARA yönteminin adımlarıyla yapılan hesaplamalar sonucunda en önemli kriterin 0,108 değeri ile "uygulama hızı" ( $\left.K_{5}\right)$ kriteri olduğu, en düşük öneme sahip olduğu kriterin ise 0,050 değeri ile 'Yönetmelikler" ( $\left.\mathrm{K}_{11}\right)$ kriteri olduğu sonucuna ulaşılmıştır.

COPELAND yöntemi ile en önemli kriterin yine 12 copeland puanı ile "uygulama hızı" $\left(\mathrm{K}_{5}\right)$, en düşük öneme sahip kriter ise yine -10,5 puanı ile "Yönetmelikler" $\left(K_{11}\right)$ kriteri olduğu sonucu ile karşılaşılmıştır. Sonuçlar incelendiğinde

SWARA yöntemi ile COPELAND yöntemi arasında çok farklılık olmadığı, sadece küçük çapta ve sonucu önemli düzeyde değiştirmeyen matematiksel farklılıklar olduğu görülmüştür. Dolayısıyla her iki yöntemde de en önemli kriter "uygulama hızı", en düşük öneme sahip kriter ise "Yönetmelikler" olmuştur. Bu uygulamada ayrıca GTZY’nin her bir başarı faktörlerinin önem düzeylerinin etkisi karar vericiler açısından farklı derecelerde olduğu da görülmektedir. Ayrıca bu 13 kriterin final ağırlıklarının ortalaması 0,077 ve standart sapması ise 0.020 'dir. Görüldüğü üzere en önemli kriter olan $K_{5}$ 'te ortalamanın üstündedir ve en az öneme sahip kriter $\mathrm{K}_{11}$ ise ortalamanın altındadır. Ortalama değerinin ' 0,077 ' üstünde kalan $\mathrm{K}_{5}(0,108)$, $\mathrm{K}_{4}(0,103), \mathrm{K}_{1}(0,095), \mathrm{K}_{3}(0,093), \mathrm{K}_{2}(0,089), \mathrm{K}_{9}(0,080), \mathrm{K}_{7}(0,078)$ bu kriterler birinci dereceden öneme sahip, altında kalan $\mathrm{K}_{6}(0,071), \mathrm{K}_{10}(0,067), \mathrm{K}_{13}(0,058), \mathrm{K}_{8}(0,055), \mathrm{K}_{12}(0,053), \mathrm{K}_{11}(0,050)$ bu kriterleri ise ikinci dereceden öneme sahip kriterler olarak adlandırmak mümkündür. Final ağırlıklarının Standart sapması düşük bir değer '0.02" çıktığı için SWARA yönteminde oluşan sonucun, çalışmaya katılan karar vericilerin uzlaşık bir çözümü olduğu sonucuna varılabilir. $\mathrm{Bu}$ da SWARA yönteminde elde edilen sonuçların COPELAND yönteminde de benzer çıkacağının bir göstergesidir.

Literatür incelemesi yapıldığında SWARA ve COPELAND yöntemleri kullanılarak GTZY'yi etkileyen başarı faktörlerinin önem düzeylerinin belirlenmesiyle ilgili bir çalışmaya rastlanmamıştır. Bu sebeple çalışmanın hem literatüre hem de gelecek çalışmalara katkı sağlayacağı düşünülmektedir.

$\mathrm{Bu}$ çalışma ile elde edilen ağırlık değerleri, WASPAS vb. çok kriterli yöntemlere adapte edilerek ve uygulanarak, firmaların etkin bir global tedarik zinciri yönetim sistemi seçmede karar verme sürecini kolaylaştırabilir. 


\section{Kaynakça}

Aghdaie, M. H., Zolfani, S. H., Zavadskas, E. K. (2013). Decision making in machine tool selection: An integrated approach with SWARA and COPRAS-G methods. Engineering Economics, 24(1), 5-17.

Aghdaie, M. H., Zolfani, S. H., Zavadskas, E. K. (2014a). Synergies of data mining and multiple attribute decision making, Procedia-Social and Behavioral Sciences, 110, 767-776.

Aghdaie, M. H., Zolfani, S. H., Zavadskas, E. K. (2014b). Sales branches performance evaluation: a multiple attribute decision making approach. In Proceedings of 8th International Scientific Conference Business and Management (pp. 1-7). Lithuania: Vilnius Gediminas Technical University.

Akın, H.B. (1998). Küresel Rekabet Ortamında Teknoloji Yönetimi ve Bisküvi, Çikolata ve Gofret Sanayiinde Teknoloji Yönetimine İlişkin Bir Uygulama. (Yayınlanmamış Doktora Tezi). Selçuk Üniversitesi Sosyal Bilimler Enstitüsü, Konya.

Alimardani, M., Zolfani, S. H., Aghdaie, M. H., Tamošaitienè, J. (2013). A novel hybrid SWARA and VIKOR methodology for supplier selection in an agile environment. Technological and Economic Development of Economy, 19(3), 533-548.

Applegate, L. M., Austin, R.,D., Mcfarlan F. W. (2003). Corporate Information Systems Management. New York, NY: McGraw-Hill Irwin.

Ateş, Ö. (2007). Perakendecilik Sektöründe Zinciri Mağazalarda Tedarik Zinciri Yönetiminin Önemi: Bir Uygulama. (Yayımlanmamış Yüksek Lisans Tezi), Dokuz Eylül Üniversitesi Sosyal Bilimler Enstitüsü, İzmir.

Bovet, D., Sheffi, Y. (1998). The Brave New World of Supply Chain Management. Supply Chain Management Review, 2, 14-22.

Browne, C. (2013). Pairwise Analysis. http://www.youtube.com/watch?v=dhv6o9ubHC0

Croxton, K.L., Keely L., Sebastian J., Lambert, D. M., Rogers, D. S. (2001). The Supply Chain Management Processes. The International Journal of Logistics Management, 12(2), 13-32.

Çakır, E. (2017a). Kriter Ağırlıklarının Swara - Copeland Yöntemi İle Belirlenmesi: Bir Üretim İşletmesinde Uygulama. Adnan Menderes Üniversitesi, Sosyal Bilimler Enstitüsü Dergisi, 4(1), 42-56.

Çakır, E., Karabıyık, B. K. (2017b). Bütünleşik Swara-Copras Yöntemi Kullanarak Bulut Depolama Hizmet Sağlayıcılarının Değerlendirilmesi. Bilişim Teknolojileri Dergisi, 10(4), 417-434. 
Dehnavı, A., Aghdam, I. N., Pradhan, B. Ve Morshed Varzandeh, M. H. (2015), A New Hybrid Model Using Step-Wise Weight Assessment Ratio Analysis (Swara) Technique and Adaptive Neuro-Fuzzy Inference System (Anfis) For Tegional Landslide Hazard Assessment İn Iran, Catena, 135, 122-148.

Eymen, U. E.(2007). Tedarik Zinciri Yönetimi. İzmir: Kaliteofisi.

Fishburn, P. (1977). Condorcet Social Choice Functions. Siam Journal of Applied Mathematics, 33 (3), 469-489.

Ganeshan, R., Harrinson, T. P. (1995). An Introduction to Supply Chain Managemant. Department of Management Sciences and Information Systems. Penn State University. http://lcm.csa.iisc.ernet.in/scm/supply_chain_intro.html

Güleş, H.K., Bülbül H. (2004). Yenilikçilik, İşletmeler İçin Stratejik Rekabet Aracı. Ankara: Nobel.

Juodagalvienè, B., Turskis, Z., Šaparauskas, J., Endriukaitytė, A. (2017). Integrated MultiCriteria Evaluation of House's Plan Shape Based on the Edas and Swara Methods. Engineering Structures and Technologies, 9(3), 117-125.

Karabašević, D., Stanujkić, D., Urošević, S., Maksimovic, M. (2015). Selection of Candidates in The Mining Industry Based on the Application of the Swara and the Multimoora Methods. Acta Montanistica Slovaca, 20(2), 116-124.

Keršuliene, V., Zavadskas, E. K., Turskis, Z. (2010). Selection of Rational Dispute Resolution Method by Applying New Step Wise Weight Assessment Ratio Analysis (Swara). Journal of Business Economics and Management, 11(2), 243-258.

Keršulienè, V., Turskis, Z. (2011). Integrated Fuzzy Multiple Criteria Decision-Making Model For Architect Selection. Technological and Economic Development of Economy, 17(4), 645-666.

Klamler, C. (2003). A Comparison of the Dodgson Method and the Copeland Rule. Economics Bulletin, 4(8), 1-7.

Kueia C., Madua C.N., Linb C. (2011). Developing Global Supply Chain Quality Management Systems. International Journal of Production Research, 49 (15), 4457-4481.

Lambert, D.M., Cooper, M.C., (2000). Issues in Supply Chain Management. Industrial Marketing Management, 29(1), 65-83.

Lambert, D.M., Croxton, K.L., Garcia-Dastugue and S.J., Rogers, D.S., (2002). The demand management process. International Journal of Logistics Management, 13, 51-66.

Manuj I., Mentzer J.T. ( 2008). Global Supply Chain Risk Management Strategies. International Journal of Physical Distribution \& Logistics Management, 38(3), 192-223. 
Meixell, M.J., Gargeya, V.B. (2005). Global Supply Chain Design: A Literature Review And Critique. Transportation Research. Logistics and Transportation Review, 41(6), 531-550.

Mentzer, J.T., Myers, M.B., Stank, T.P. (2006). Handbook Of Global Supply Chain Management. https://books.google.com.tr/books?id=0p51 cgaaqbaj\&printsec $=$ frontcover\&hl=tr\#v=on epage \&q\&f=false

Min, H., Zhou, G. (2002). Supply Chain Modeling: Past, Present and Future. Computers and Industrial Engineering, 43(1-2), 231-249.

Onat, O. (2002). Tedarik Zinciri Yönetimi Ve B2b Uygulamaları. İgeme’den Bakış, 20, 38.

Özdemir, A.İ. (2004). Tedarik Zinciri Yönetiminin Gelişimi, Süreçleri ve Yararları. Erciyes Üniversitesi, İktisadi Ve İdari Bilimler Fakültesi Dergisi, 23, 87-96.

Ross D.F. (1998). Competing Through Supply Chain Management: Creating Market - Winning Strategies Through Supply Chain Partnerships. New York: Kluwer Academic.

Sanver, M. R. (2000). Çoğunluk Yöntemi Ve Condorcet Galipleri, Ankara Üniversitesi Sbf Dergisi, 55(3), 133-144.

Shukla, S., Mishra, P. K., Jain, R. Ve Yadav, H. C. (2016). An Integrated Decision Making Approach For Erp System Selection Using Swara and Promethee Method. Int. J. of Intelligent Enterprise, 3(2), 120-147.

Stanujkić, D, Djordjević, B., Karabašević, D. (2015a). Selection of Candidates in the Process of Recruitment and Selection of Personnel. Quaestus Multidisciplinary Research Journal, 7, 53-64.

Stanujkić, D., Karabašević, D., Zavadskas, E. K. (2015b). A Framework For the Selection of a Packaging Design Based on the Swara Method. Engineering Economics, 26(2), 181-187.

T.C. Ekonomi Bakanlığı (2014). Kobi İşbirliği ve Kümelenme Projesi Ağ Oluşturma ve Bölgesel İşbirliği İçin Kobi'lerin Güçlendirilmesine Yönelik Teknik Yardım. http://www.smenetworking.gov.tr/userfiles/pdf/belgeler/ekonomibakanligi/7_tedarik.pd $\mathrm{f}$

Teigen R. (1997). Supply Chain Management. http://eil.utoronto.ca./profiles/rune/node5.html

Tekin, M., Zerenler, M., Bilge, A. (2005). Bilişim Teknolojileri Kullanımının İşletme Performansına Etkileri: Lojistik Sektöründe Bir Uygulama. İstanbul Ticaret Üniversitesi Fen Bilimleri Dergisi, 8(2), 115-129.

Tokdemir, Y. (2016). Başarılı Tedarik Zinciri Yönetimi ve Maliyetlerin Azaltılması. http://www.yasamicingida.com/basarili-tedarik-zinciri-yonetimi-ve-maliyetleriazaltilmasi-2/ 
Türköz, Ö. (2007). Tedarik Zinciri Yönetimi’nde Dağıtım Gereksinim Planlaması. Yüksek Lisans Tezi, İstanbul Üniversitesi/Sosyal Bilimler Enstitüsü, İstanbul.

Vafaeipour, M., Zolfani, S. H., Varzandeh, M. H. M., Derakhti, A., Keshavarz, M. E. (2014). Assessment of Regions Priority For Implementation of Solar Projects in Iran: New Application of a Hybrid Multi-Criteria Decision-Making Approach. Energy Conversion and Management, 86, 653-663.

Yazdanı, M., Zavadskas, E. K., Ignatıus, J. ve Abad, M. D. (2016). Sensitivity Analysis in Madm Methods: Application of Material Selection, Engineering Economics, 27(4), 382-391.

Yön, I. (2007). Tedarik Zinciri Yönetimi Uygulamalarının Rekabet Gücü Üzerine Etkisi. Yüksek Lisans Tezi, Gaziantep Üniversitesi/Sosyal Bilimler Enstitüsü, Gaziantep.

Zolfanı, S. H., Esfahani, M. H., Bitarafan, M., Zavadskas, E. K., Arefi, S. L. (2013a) Developing A New Hybrid Mcdm Method For Selection of the Optimal Alternative of Mechanical Longitudinal Ventilation of Tunnel Pollutants During Automobile Accidents. Transport, 28 (1), 89-96.

Zolfanı, S. H., Zavadskas, E. K. ve Turskis, Z. (2013b). Design of Products with Both International and Local Perspectives Based on Yin-Yang Balance Theory and Swara Method. Economic Research (Ekonomska Istraživanja), 26 (2), 153-166.

Zolfanı, S. H., Saparauskas, J. (2013c). New Application of Swara Method in Prioritizing Sustainability Assessment Indicators of Energy System. Engineering Economics, 24(5), 408-414.

Zolfanı, S. H., Banihashemi, S. S. A. (2014a). Personnel Selection Based on A Novel Model of Game Theory and Mcdm Approaches. In Proceedings of 8th International Scientific Conference BusinessaAnd Management (Pp. 191-198). Lithuania: Vilnius Gediminas Technical University.

Zolfanı, S.H., Bahrami, M. (2014b). Investment Prioritizing in High Tech Industries Based On Swara Copras Approach. Technological and Economic Development of Economy, 20(3), 534-553. 